\title{
Proposed Model for Stress-strain Behavior of Fly Ash Concrete Under the Freezing and Thawing Cycles
}

\author{
Ali Hemmati ${ }^{1 *}$, Heydar Arab² \\ 1 Seismic Geotechnical and High Performance Concrete Center, Department of Civil Engineering, Semnan Branch, Islamic Azad \\ University, Semnan, P.O.B. 35145179, Iran \\ 2 Department of Civil Engineering, Semnan Branch, Islamic Azad University, Semnan, P.O.B. 35145179, Iran \\ * Corresponding author, e-mail: ali.hemmati@semnaniau.ac.ir
}

Received: 06 August 2019, Accepted: 15 April 2020, Published online: 12 May 2020

\begin{abstract}
Fly ash is a supplementary cement material using instead of Portland cement in concrete. Using this material concludes to less emission of greenhouse gas and less water demand of concrete. In this paper, an experimental investigation was carried out on compressive stress-strain behavior of three groups of concrete specimens with different water/cement ratios $(0.45,0.5$ and 0.55$)$, containing 0,10 , 20, 30 and 40 percent of fly ash (by weight), after subjecting to freezing and thawing cycles. 0, 45, 100 and 150 cycles of freezing and thawing were applied on these specimens according to ASTM C666 and the results presented. Numerical models for the stress-strain behavior of these frozen-thawed concrete were developed and compared with the available experimental data. Results show that the maximum compressive strength of these concrete specimens exposing cycles of freezing and thawing is gained by using about $10 \%$ of fly ash. Moreover, there is a good agreement between the proposed models and test results and the difference is less than $5 \%$.
\end{abstract} Keywords

concrete, fly ash, freezing and thawing, stress strain behavior

\section{Introduction}

Fly ash, which is a by-product from combustion of pulverized coal, can partly replace the cement in concrete. The performance of concrete with fly ash is in many situations improved compared to that of concrete mixed with Portland cement only. Using fly ash instead of Portland cement concludes to less hydration heat, less emission of greenhouse gas and less water demand of concrete. This supplementary material consists of silica $\left(\mathrm{SiO}_{2}\right)$, aluminum oxide $\left(\mathrm{Al}_{2} \mathrm{O}_{3}\right)$, iron oxide $\left(\mathrm{Fe}_{2} \mathrm{O}_{3}\right)$ and calcium oxide $(\mathrm{CaO})$. Due to incomplete combustion and organic additives used in the collecting process, the fly ash also contains some unburned carbon. The carbon content of the fly ash is approximately determined by loss-on-ignition (LOI) test, which means that the fly ash is heated to high temperatures, leading to combustion of the unburned carbon [1]. The concrete contains some water in the pores and as this water freezes, it will expand with about $9 \%$. If there is not enough space to accommodate this extra volume, a disruptive pressure will be created. This disruptive pressure will be further enhanced by osmotic pressure. Consequently, concrete subjected to freezing and thawing can be damaged externally or internally [2].
Durability of frozen-thawed concrete containing blended cement with fly ash was investigated by Fagerlund [3]. The results showed that the concrete containing $23 \%$ fly ash with entrained air was durable. Concrete specimens with different amounts of fly ash $(0 \%, 20 \%, 30 \%$ and $35 \%$ of cement weight) were tested by Müller and Severins [4]. All mixtures had significantly less scaling at the surface than what was acceptable. Kosior-Kazberuk and JózwiakNiedzwiedzka [5] investigated the influence of fly ash on scaling resistance of concrete. Results showed that fly ash had significant effect on concrete freeze/thaw durability. Compressive stress-strain behavior of unconfined and confined concrete under freezing and thawing cycles was proposed by Duan et al. [6] and compared with available experimental data. Three series of uncowfined concrete specimens with water/cement ratio of $0.48,0.54$ and 0.6 and two series of tied columns with confinement index of 0.317 and 0.145 were tested and analytical investigations were carried out too. Liu et al. [7] presented an experimental study on the permeation properties and pore structure of concrete surface layers containing fly ash. Concrete 
specimens with different amounts of fly ash as a replacement for cement $(0 \%, 15 \%$ and $30 \%$ by weight of total cement) were studied. Results showed that incorporation of fly ash, for the early test period, promoted the chloride ingress at the surface layer of concrete but substituting proportions of fly ash had little impact on it. With the process of chloride immersion, the chloride concentration at the surface layer of concrete with or without fly ash was found to be nearly the same. Mechanical and durability properties of medium strength self-compacting concrete with high-volume fly ash and blended aggregates were studied by Nagaratnam et al. [8] Results demonstrated that fly ash based SCC shows better resistance to water absorption, apparent volume of permeable voids and chloride penetration than the control mix. Durability of concrete containing $10 \%, 15 \%$ and $25 \%$ by weight of fly ash and $5 \%, 8 \%$ and $11 \%$ by weight of silica fume under the combined effect of freezing and thawing cycles and sulfate attack was studied by Wang et al. [9]. Results indicated that the replacement level of $25 \%$ for fly ash and $5 \%$ to $8 \%$ for silica fume by weight led to evident improvements in the resistance of concrete against combined freezing and thawing and sulfate attack. Ma et al. [10] studied the fracture behavior of concrete exposed to freeze-thaw environment. Results showed that, the fracture behavior of concrete with both fly ash and silica fume is better than that of concrete with only with fly ash. Admixtures and sustainability of concrete were reviewed by Cheung et al. [11]. Incorporation of these supplementary materials such as fly ash was about $20 \%$ by the weight of cement. This replacement amount could be more than doubled with correct mix proportioning and innovative technologies such as pre-test tools and smart concrete systems. Wang et al. [12] studied the chloride ion penetration resistance of concrete containing fly ash and silica fume against combined effect of freezing and thawing cycles and chloride attack. Experimental specimens immersed in tap water and sodium chloride solution and subjected to 50 freezing-thawing cycles. Results showed that immersed in tap water, silica fume had more evident improvement on resistance of concrete against combined effects than fly ash. After 50 freezing and thawing cycles, chloride ion penetration resistance of concrete with fly ash increased more than that of silica fume. Interaction between freezing and thawing cycles and chloride attack accelerated deterioration of concrete. Macro-micro degradation process of fly ash concrete under alternation of freezing and thawing cycles subjected to sulfate and carbonation was investigated by Liu et al. [13]. Two types of experiments including freezing and thawing cycles subjected to sulfate and freezing and thawing cycles subjected to sulfate and carbonation were implemented. Results demonstrated that freezing and thawing cycles caused aperture degradation, coarsened the pore structure, and with the additional interaction of sulfate erosion, aggravated the deterioration of concrete. Designing of reinforced concrete beams containing supplementary cementitious materials was studied by Fantilli et al. [14]. A new limit state was introduced and used in combination with the traditional limit state. Nguyen et al. [15] used fly ash as a partial replacement for cement in the proportions of $10 \%, 20 \%$ and $40 \%$, while the water to cement ratio was constant at $0.42,0.5$ and 0.55 . The results demonstrated that the compressive strength of fly ash concrete was reduced at an early age but increased as the concrete continued to hydrate. Using fly ash concluded to more resistance of concrete against the sulfuric acid attack. Fly ash additions have only a limited effect on reducing the risk of probability of corrosion of steel in the concrete too. The optimum fly ash replacement proportion was found to be $20 \%$ by weight of cement.

As it stated, some investigations have been performed on the mechanical properties of concrete containing fly ash under the cycles of freezing and thawing. But there were a few studies on the stress-strain behavior of this concrete. In this paper, an experimental test was carried out to study the effect of using fly ash on the stress strain behavior of the frozen-thawed concrete with different water/cement ratios.

\section{Materials and methods}

Coarse aggregates (C. A) with maximum size of $19 \mathrm{~mm}$, fineness modulus of 7.38, water absorption ratio of $0.6 \%$ and specific gravity of 2.61 were used for this experimental work. Natural river sand (F. A) with fineness modulus of 2.69, water absorption ratio of $0.8 \%$ and specific gravity of 2.55 was used too. Portland cement type II was used for this experimental study. Fly ash with a specific gravity of 2.32 and a fineness of $22 \%$ was used in this study too $[16,17]$. Chemical composition of the used fly ash and cement is presented in Table1. The mix proportion of concrete with water to cement ratios $(w / c)$ of $0.45,0.5$ and 0.55 are given in Table 2. To examine the effect of fly ash on the durability and stress-strain behavior of concrete, mix containing $0,10,20,30$ and $40 \%$ of fly ash (by weight) as a partial replacement of cement, were prepared.

Concrete cylinder specimens were cast in plastic molds of $125 \mathrm{~mm}$ diameter and $300 \mathrm{~mm}$ length and then removed from the molds 24 hours after casting. Curing process was 
performed in saturated lime water at $23 \pm 2^{\circ} \mathrm{C}$ for 14 days according to ASTM C666 [18]. In this study, concrete specimens containing different amounts of fly ash, were subjected to $0,45,100$ and 150 cycles of freezing and thawing according to ASTM C666. Subsequently, these specimens were tested under the uni-axial compression according to Fig. 1.

Table 1 Chemical composition of fly ash and cement

\begin{tabular}{lcc}
\hline Chemical composition & Fly ash (\%) & Cement (\%) \\
\hline $\mathrm{SiO}_{2}$ & 59.7 & 36.06 \\
$\mathrm{Fe}_{2} \mathrm{O}_{3}$ & 8.2 & 3.87 \\
$\mathrm{Al}_{2} \mathrm{O}_{3}$ & 20.2 & 5.43 \\
$\mathrm{CaO}$ & 1.7 & 64.96 \\
$\mathrm{MgO}$ & 1 & 0.48 \\
$\mathrm{SO}_{3}$ & 0.1 & 2.09 \\
$\mathrm{TiO}_{2}$ & 1.1 & - \\
$\mathrm{Na}_{2} \mathrm{O}$ & 0.2 & 0.27 \\
$\mathrm{~K}_{2} \mathrm{O}$ & 1 & 0.6 \\
$\mathrm{LOI}$ & 1.8 & 1.95 \\
\hline
\end{tabular}

Table 2 Mix proportion $\left(\mathrm{kg} / \mathrm{m}^{3}\right)$

\begin{tabular}{lcccccc}
\hline Specimen & (w/c) & Water & Cement & C. A & F. A & Fly ash \\
\hline CF & & 193 & 429 & 1058 & 677 & - \\
CF10 & & 193 & 386.1 & 1058 & 677 & 42.9 \\
CF20 & 0.45 & 193 & 343.2 & 1058 & 677 & 85.8 \\
CF30 & & 193 & 300.3 & 1058 & 677 & 128.7 \\
CF40 & & 193 & 257.4 & 1058 & 677 & 171.6 \\
\hline CF & 193 & 386 & 1080 & 720 & - \\
CF10 & & 193 & 347.4 & 1080 & 720 & 38.6 \\
CF20 & 0.5 & 193 & 308.8 & 1080 & 720 & 77.2 \\
CF30 & & 193 & 270.2 & 1080 & 720 & 115.8 \\
CF40 & & 193 & 231.6 & 1080 & 720 & 154.4 \\
\hline CF & & 193 & 351 & 1031 & 814 & - \\
CF10 & & 193 & 315.9 & 1031 & 814 & 35.1 \\
CF20 & 0.55 & 193 & 280.8 & 1031 & 814 & 70.2 \\
CF30 & & 193 & 245.7 & 1031 & 814 & 105.3 \\
CF40 & & 193 & 210.6 & 1031 & 814 & 140.4 \\
\hline & & & & & \\
\hline
\end{tabular}

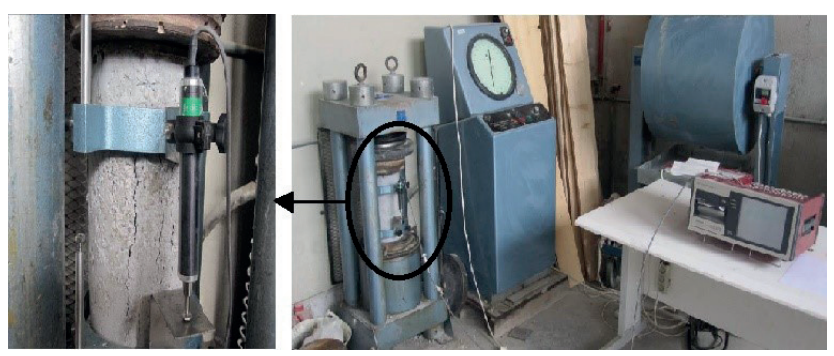

Fig. 1 Test set up
Uni-axial compressive displacement with a constant rate of $1.3 \mathrm{~mm} / \mathrm{min}$ was applied on cylindrical specimens to record the stress-strain data of the concrete. Experimental data including load and displacement values were recorded every 0.5 second through the test and saved on data logger. For each series of mixes, three specimens with dimension of $100 \times 100 \times 100 \mathrm{~mm}$ were casted and cured for gaining the compressive strength of concrete with no cycles of freezing and thawing.

\section{Results}

Slump test was carried out on fresh concrete and the results presented in Table 3. As it observed, using fly ash concluded to more workability of concrete. Compressive strength test was performed on concrete cube specimens at 21,28 and 35 days. Summary of the compression test is presented in Table 4

Cylindrical specimens after exposing to $0,45,100$ and 150 cycles were tested according to Fig. 1 to obtain stressstrain behavior of concrete containing different amounts of fly ash. 45,100 and 150 cycles were compatible to 21 , 28 and 35 days too. Variation of the normalized compressive strength of the cylindrical specimens $\left(f_{C D} / f_{C O}\right)$ after freezing and thawing cycles is shown in Fig. 2. Where, $f_{C D}$ is the compressive strength of the concrete specimen after freezing and thawing cycles and $f_{C O}$ is the compressive strength of the cylindrical specimen with no cycles of freezing and thawing. Each point in Fig. 2 represents the average of 3 specimens. As observed, with increase of the number of cycles, the compressive strength decreases.

Table 3 Results of the slump test

\begin{tabular}{lcc}
\hline Specimen & $(\mathrm{w} / \mathrm{c})$ & Slump $(\mathrm{mm})$ \\
\hline CF & 78 \\
CF10 & 81 \\
CF20 & 0.45 & 83 \\
CF30 & 86 \\
CF40 & 89 \\
\hline CF & 82 \\
CF10 & 85 \\
CF20 & 86 \\
CF30 & 9.5 & 90 \\
CF40 & 93 \\
\hline CF & 86 \\
CF10 & 89 \\
CF20 & 90 \\
CF30 & 95 \\
CF40 & 98 \\
\hline & 0.55 & \\
\hline & & 95 \\
\hline
\end{tabular}


Table 4 Compressive strength of the specimens

\begin{tabular}{|c|c|c|c|c|c|c|}
\hline \multirow[t]{2}{*}{ Specimen } & \multirow[t]{2}{*}{$(w / c)$} & \multicolumn{2}{|c|}{$\begin{array}{c}\text { Compressive strength under different cycles of freezing } \\
\text { and thawing (MPa) }\end{array}$} & \multicolumn{3}{|c|}{$\begin{array}{c}\text { Compressive strength with no cycles of freezing } \\
\text { and thawing (MPa) }\end{array}$} \\
\hline & & Number of cycles $(\mathrm{N})$ & Compressive strength (MPa) & 21 days & 28 days & 35 days \\
\hline \multirow{4}{*}{$\mathrm{CF}$} & \multirow{4}{*}{0.45} & 0 & 41.65 & \multirow{4}{*}{38.65} & \multirow{4}{*}{42.75} & \multirow{4}{*}{44.34} \\
\hline & & 45 & 35.1 & & & \\
\hline & & 100 & 32.31 & & & \\
\hline & & 150 & 30.9 & & & \\
\hline \multirow{4}{*}{ CF10 } & \multirow{4}{*}{0.45} & 0 & 40.26 & \multirow{4}{*}{37.96} & \multirow{4}{*}{41.8} & \multirow{4}{*}{44.68} \\
\hline & & 45 & 36.1 & & & \\
\hline & & 100 & 34.27 & & & \\
\hline & & 150 & 32.9 & & & \\
\hline \multirow{4}{*}{ CF20 } & \multirow{4}{*}{0.45} & 0 & 39.32 & \multirow{4}{*}{35.72} & \multirow{4}{*}{41.1} & \multirow{4}{*}{44.4} \\
\hline & & 45 & 33.23 & & & \\
\hline & & 100 & 31.1 & & & \\
\hline & & 150 & 30.46 & & & \\
\hline \multirow{4}{*}{ CF30 } & \multirow{4}{*}{0.45} & 0 & 30.57 & \multirow{4}{*}{30.59} & \multirow{4}{*}{34.7} & \\
\hline & & 45 & 27.24 & & & 3494 \\
\hline & & 100 & 26.24 & & & 34.94 \\
\hline & & 150 & 24.05 & & & \\
\hline & & 0 & 28.73 & & & \\
\hline CFE & 015 & 45 & 23.05 & 2507 & 3110 & 3227 \\
\hline $\mathrm{C} \times 40$ & 0.45 & 100 & 22.63 & 25.02 & 31.19 & 32.22 \\
\hline & & 150 & 21.98 & & & \\
\hline & & 0 & 34.71 & & & \\
\hline$C F$ & 0 & 45 & 29.19 & 3203 & 2561 & 2605 \\
\hline $\mathrm{CF}$ & 0.5 & 100 & 26.92 & 32.23 & 35.61 & 36.95 \\
\hline & & 150 & 25.75 & & & \\
\hline & & 0 & 33.27 & & & \\
\hline CF10 & 0.5 & 45 & 29.82 & 3136 & 3483 & 3723 \\
\hline - & $0 . J$ & 100 & 28.32 & 51.50 & 34.03 & S1.25 \\
\hline & & 150 & 27.18 & & & \\
\hline & & 0 & 32.76 & & & \\
\hline CE 20 & $0-5$ & 45 & 27.69 & 2077 & 3424 & 3609 \\
\hline$C F \angle 0$ & $0 . J$ & 100 & 25.9 & 28.11 & 34.24 & 3.37 \\
\hline & & 150 & 25.38 & & & \\
\hline & & 0 & 25.69 & & & \\
\hline$C 520$ & 0.5 & 45 & 22.89 & 2540 & 2800 & 2010 \\
\hline$C F 30$ & 0.5 & 100 & 22.05 & 25.49 & 28.91 & 29.12 \\
\hline & & 150 & 20.21 & & & \\
\hline & & 0 & 24.35 & & & \\
\hline CF40 & 0.5 & 45 & 19.53 & 20.85 & 2500 & 2605 \\
\hline $\mathrm{CF} 40$ & 0.5 & 100 & 19.18 & 20.85 & 25.99 & 20.83 \\
\hline & & 150 & 18.62 & & & \\
\hline & & 0 & 30.72 & & & \\
\hline$C F$ & 0.55 & 45 & 25.83 & 285 & 3151 & 327 \\
\hline $\mathrm{CF}_{\mathrm{S}}$ & 0.55 & 100 & 23.82 & 28.5 & 31.51 & 32.1 \\
\hline & & 150 & 22.79 & & & \\
\hline
\end{tabular}




\begin{tabular}{|c|c|c|c|c|c|c|}
\hline \multirow[t]{2}{*}{ Specimen } & \multirow[t]{2}{*}{$(w / c)$} & \multicolumn{2}{|c|}{$\begin{array}{c}\text { Compressive strength under different cycles of freezing } \\
\text { and thawing (MPa) }\end{array}$} & \multicolumn{3}{|c|}{$\begin{array}{c}\text { Compressive strength with no cycles of freezing } \\
\text { and thawing }(\mathrm{MPa})\end{array}$} \\
\hline & & Number of cycles $(\mathrm{N})$ & Compressive strength (MPa) & 21 days & 28 days & 35 days \\
\hline \multirow{4}{*}{ CF10 } & \multirow{4}{*}{0.55} & 0 & 29.44 & \multirow{4}{*}{27.75} & \multirow{4}{*}{30.81} & \multirow{4}{*}{32.95} \\
\hline & & 45 & 26.39 & & & \\
\hline & & 100 & 25.06 & & & \\
\hline & & 150 & 24.05 & & & \\
\hline \multirow{4}{*}{ CF20 } & \multirow{4}{*}{0.55} & 0 & 28.96 & \multirow{4}{*}{26.34} & \multirow{4}{*}{30.3} & \multirow{4}{*}{32.74} \\
\hline & & 45 & 24.48 & & & \\
\hline & & 100 & 22.9 & & & \\
\hline & & 150 & 22.44 & & & \\
\hline \multirow{4}{*}{ CF30 } & \multirow{4}{*}{0.55} & 0 & 22.68 & \multirow{4}{*}{22.56} & \multirow{4}{*}{25.59} & \multirow{4}{*}{25.77} \\
\hline & & 45 & 20.21 & & & \\
\hline & & 100 & 19.47 & & & \\
\hline & & 150 & 17.84 & & & \\
\hline \multirow{4}{*}{ CF40 } & \multirow{4}{*}{0.55} & 0 & 21.5 & \multirow{4}{*}{18.47} & \multirow{4}{*}{22.1} & \multirow{4}{*}{23.82} \\
\hline & & 45 & 17.24 & & & \\
\hline & & 100 & 16.93 & & & \\
\hline & & 150 & 16.44 & & & \\
\hline
\end{tabular}

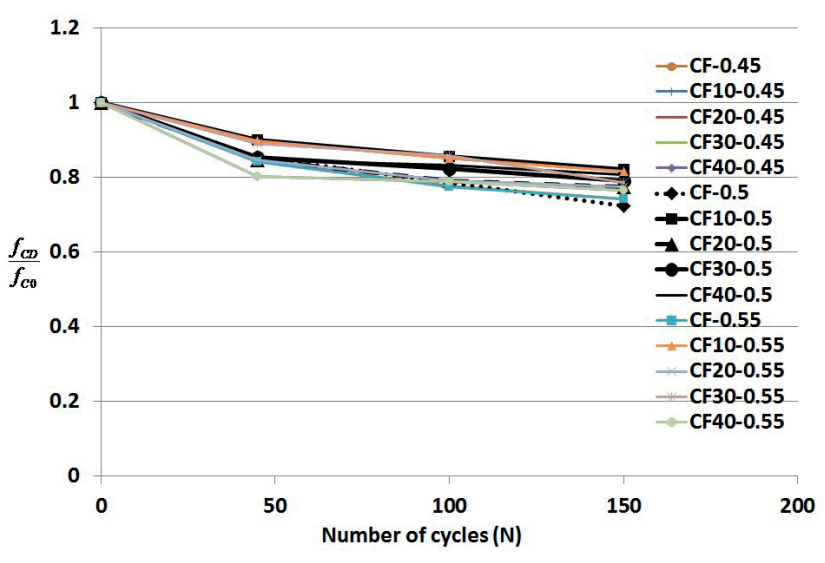

Fig. 2 Variation of $\left(f_{C D} / f_{C O}\right)$ of the cylindrical specimens after freezing and thawing cycles

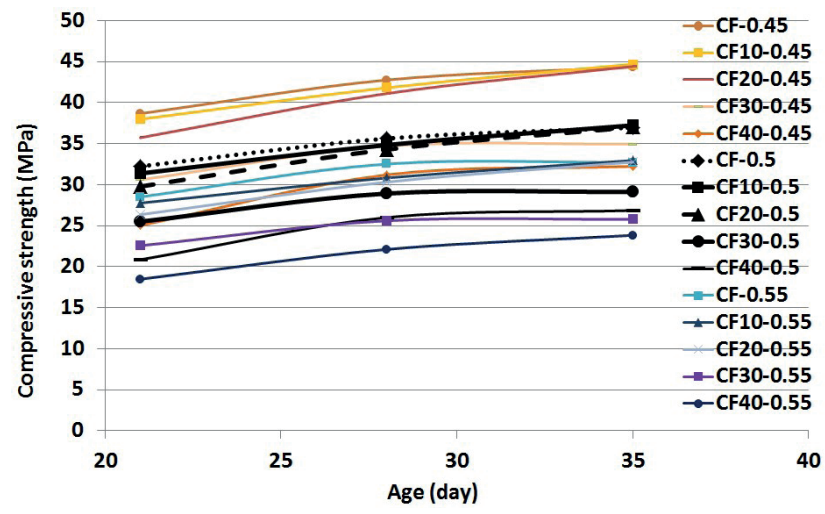

Fig. 3 Variation of the compressive strength of the cube specimens $\left(f_{c u}\right)$ with no cycles of freezing and thawing
150 cycles of freezing and thawing conclude to an average decrease about $21.2 \%$ in the compressive strength of concrete. The minimum decrease belongs to CF10 specimen (about $18 \%$ ) and the maximum decrease belongs to CF specimen (about $25 \%$ ). Variation of the compressive strength of the cube specimens $\left(f_{c u}\right)$ with no cycles of freezing and thawing versus the age of the concrete is shown in Fig. 3 too. As it observed, the rate of strength development for concrete with fly ash is lower than that of the concrete with plain cement at the beginning days. But CF10 and CF20 specimens continue to gain strength which means that after about 28 days, the strength of these specimens is higher than that of the concrete with no fly ash. The pozzolanic activity of fly ash improves the strength of the transition zone (interface between the paste and aggregate) in concrete. Moreover, better packing of particles in the fresh state when fly ash is included reduces the porosity and leading to higher strength [19]. As it observed, the Compressive strength of the whole specimens increase with decreasing the $(w / c)$ ratio. The compressive strength of the specimens with $w / c=0.45$ and $w / c=0.55$ are about 1.2 and 0.885 times of the concrete specimens with $w / c=0.5$, respectively.

By the regression analysis, the numerical relation between $\left(f_{C D} / f_{C O}\right)$ and the number of cycles $(N)$ can be presented as Eq. (1) and Fig. 4. The maximum difference between experimental data of frozen-thawed concrete and proposed relation is about $4.5 \%$. 


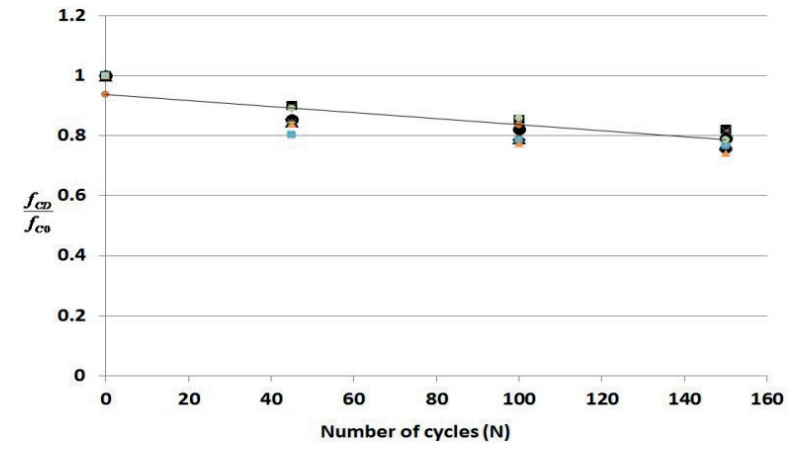

Fig. 4 Proposed relation between $\left(f_{C D} / f_{C O}\right)$ and $(\mathrm{N})$

$f_{C D} / f_{C O}=-0.001 \times N+0.9362$

28-day and 35-day compressive stress-strain curves of the cylindrical specimens with no cycles of freezing and thawing $(w / c=0.5)$ are shown in Fig. 5 and Fig. 6 respectively. The strain at the peak stress $\left(\varepsilon_{0}\right)$ and ultimate compressive strain $\left(\varepsilon_{c u}\right)$ of the whole specimens are determined according to Fig. 7 and presented in Table 5.

As it observed, using fly ash concludes to more $\left(\varepsilon_{0}\right)$ and $\left(\varepsilon_{c u}\right)$ values than those of plain concrete. After 28 days, the maximum $\left(\varepsilon_{0}\right)$ and $\left(\varepsilon_{c u}\right)$ belong to CF40 specimens and are

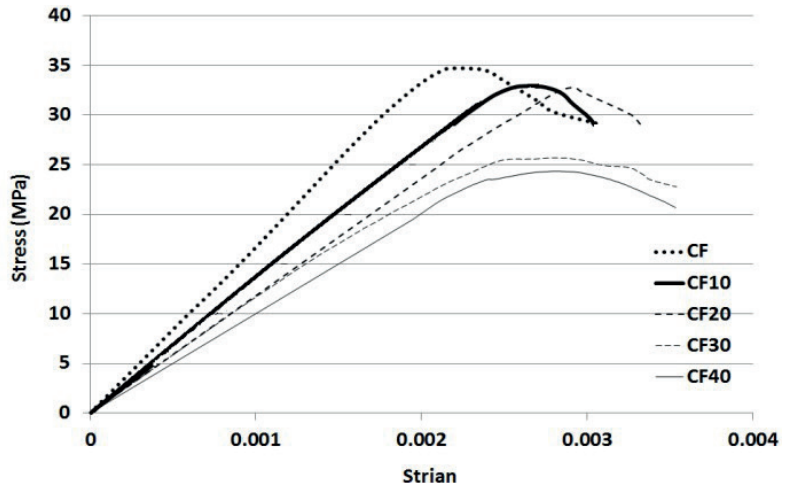

Fig. 5 28-day compressive stress-strain curves of cylindrical specimens with no cycles of freezing and thawing $(w / c=0.5)$

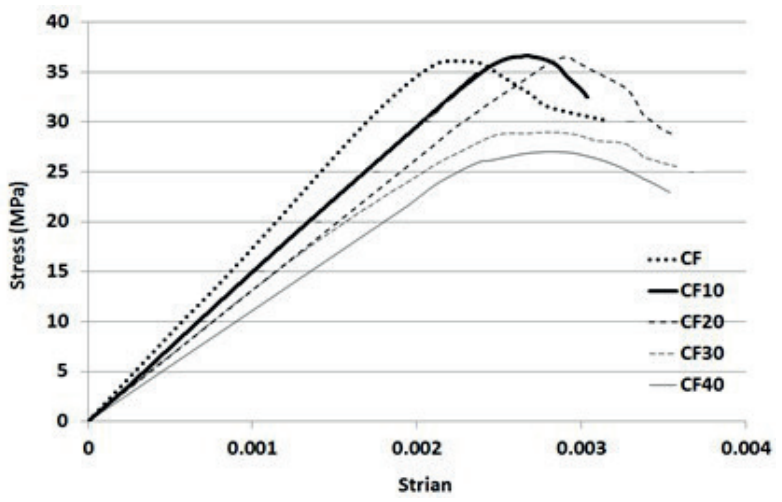

Fig. 635 -day compressive stress-strain curves of cylindrical specimens with no cycles of freezing and thawing $(w / c=0.5)$

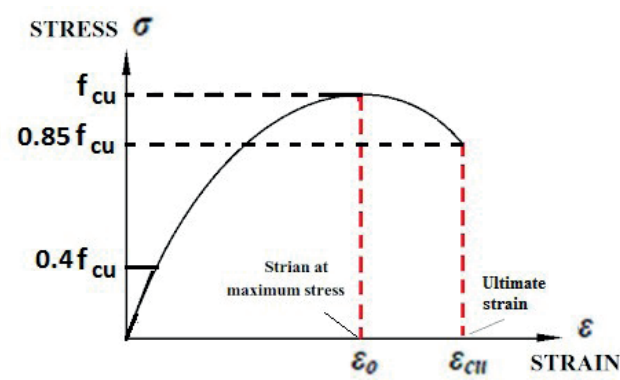

Fig. 7 Compressive stress-strain curve of cylindrical specimen

Table $5\left(\varepsilon_{0}\right)$ and $\left(\varepsilon_{c u}\right)$ of the specimens with no cycles of freezing and thawing

\begin{tabular}{|c|c|c|c|c|}
\hline Specimens & $w / c$ & Age (days) & $\left(\varepsilon_{0}\right)$ & $\left(\varepsilon_{c u}\right)$ \\
\hline $\mathrm{CF}$ & \multirow{10}{*}{0.45} & 28 & 0.0021 & 0.00282 \\
\hline CF10 & & 28 & 0.00252 & 0.00292 \\
\hline CF20 & & 28 & .0026 & 0.00311 \\
\hline CF30 & & 28 & 0.00264 & 0.0034 \\
\hline CF40 & & 28 & 0.00272 & 0.00344 \\
\hline $\mathrm{CF}$ & & 35 & 0.00215 & 0.00306 \\
\hline CF10 & & 35 & 0.00254 & 0.00301 \\
\hline CF20 & & 35 & 0.00274 & 0.0035 \\
\hline CF30 & & 35 & 0.00279 & 0.00366 \\
\hline CF40 & & 35 & 0.0028 & 0.0037 \\
\hline $\mathrm{CF}$ & \multirow{10}{*}{0.5} & 28 & 0.0022 & 0.0029 \\
\hline CF10 & & 28 & 0.0026 & 0.003 \\
\hline CF20 & & 28 & 0.0027 & 0.0032 \\
\hline CF30 & & 28 & 0.00272 & 0.0035 \\
\hline CF40 & & 28 & 0.0028 & 0.00354 \\
\hline $\mathrm{CF}$ & & 35 & 0.00222 & 0.00315 \\
\hline CF10 & & 35 & 0.00262 & 0.0031 \\
\hline CF20 & & 35 & 0.00282 & 0.0036 \\
\hline CF30 & & 35 & 0.00288 & 0.00375 \\
\hline CF40 & & 35 & 0.0029 & 0.0038 \\
\hline $\mathrm{CF}$ & \multirow{10}{*}{0.55} & 28 & 0.0022 & 0.00298 \\
\hline CF10 & & 28 & 0.00265 & 0.0031 \\
\hline CF20 & & 28 & 0.00275 & 0.0033 \\
\hline CF30 & & 28 & 0.00277 & 0.0036 \\
\hline CF40 & & 28 & 0.00285 & 0.00364 \\
\hline $\mathrm{CF}$ & & 35 & 0.00226 & 0.0032 \\
\hline CF10 & & 35 & 0.00267 & 0.0032 \\
\hline CF20 & & 35 & 0.00288 & 0.00371 \\
\hline CF30 & & 35 & 0.00293 & 0.00386 \\
\hline CF40 & & 35 & 0.00296 & 0.00388 \\
\hline
\end{tabular}

about $31.82 \%$ and $22.07 \%$ more than those of the corresponding CF specimens respectively. After 35 days, the maximum $\left(\varepsilon_{0}\right)$ and $\left(\varepsilon_{c u}\right)$ belong to CF40 specimen and are about $30.63 \%$ and $17.46 \%$ more than those of CF specimen respectively. It may be concluded that using fly ash results in softer concrete. 
The experimental compressive normalized stressstrain curves of the concrete containing different amounts of fly ash after exposing 45, 100 and 150 cycles of freezing and thawing are shown in Fig. 8. Where, $\left(\varepsilon_{0}\right)$ is the strain at the peak stress, $\left(\varepsilon_{c u}\right)$ is the ultimate compressive strain, $\sigma$ is the compressive stress of concrete and $f_{c}$ is the compressive strength of the concrete specimens. Each point in these curves represents the average of 3 specimens with different $w / c$ ratios $(0.45,0.5$ and 0.55$)$. For concrete with no cycles of freezing and thawing, the tangent modulus $(E)$ decreases continuously with increasing of strain in the ascending branch of the stress-strain curve. But in Fig. 8, it is observed that there is a pronounced concave-up curve at the beginning of loading for concrete experienced some cycles of freezing and thawing. This concave part would be due to closing of the pre-existing cracks which were caused by freezing and thawing cycles. More cycles of freezing and thawing results in more pronounced concave part in the stress-strain curves of the concrete.

As it can be seen, the maximum of the normalized strain $\left(\varepsilon_{c} / \varepsilon_{c o}\right)$ and the minimum modulus of elasticity belongs to CF40-N $=150$ specimen and it may be stated that using more amounts of fly ash and exposing to more cycles of freezing and thawing concludes to softer concrete. The strain at the peak stress $\left(\varepsilon_{0}\right)$ and ultimate compressive strain $\left(\varepsilon_{c u}\right)$ of the specimens under the different cycles of freezing and thawing are presented in Table 6.

As it seen, exposing to freezing and thawing cycles, concludes to more $\left(\varepsilon_{0}\right)$ and $\left(\varepsilon_{c u}\right)$ than those of concrete with no cycles of freezing and thawing. After 45 cycles of freezing and thawing, the maximum $\left(\varepsilon_{0}\right)$ and $\left(\varepsilon_{c u}\right)$ belong to CF40 specimen and are about 1.04 and 1.12 times of the CF specimen. $\left(\varepsilon_{0}\right)$ and $\left(\varepsilon_{c u}\right)$ of the CF40 specimen after 100 and 150 cycles of freezing and thawing are about

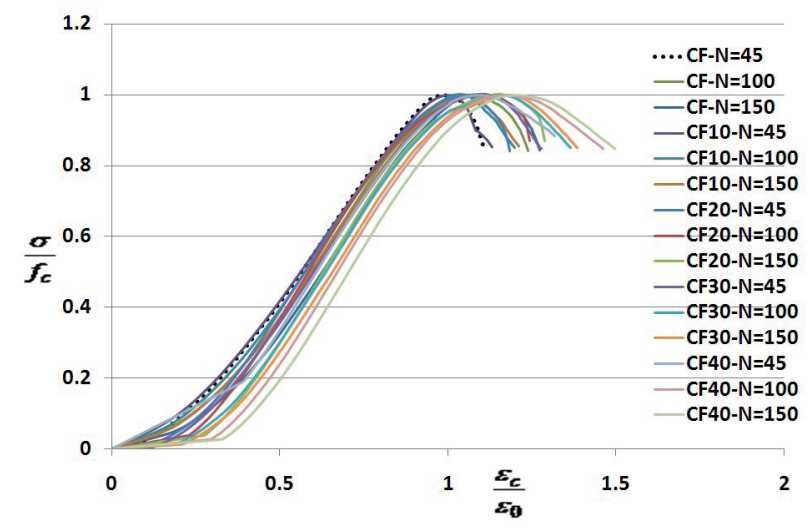

Fig. 8 Compressive normalized stress-strain curves of cylindrical specimens exposing 45, 100 and 150 cycles of freezing and thawing
Table $6\left(\varepsilon_{0}\right)$ and $\left(\varepsilon_{c u}\right)$ of the specimens with different cycles of freezing and thawing

\begin{tabular}{|c|c|c|c|c|}
\hline Specimens & $\mathrm{w} / \mathrm{c}$ & $\mathrm{N}$ & $\left(\varepsilon_{0}\right)$ & $\left(\varepsilon_{c u}\right)$ \\
\hline $\mathrm{CF}$ & & 45 & 0.00256 & 0.00287 \\
\hline CF10 & & 45 & 0.00255 & 0.00292 \\
\hline CF20 & & 45 & .00262 & 0.00311 \\
\hline CF30 & & 45 & 0.00266 & 0.00317 \\
\hline CF40 & & 45 & 0.00268 & 0.00322 \\
\hline $\mathrm{CF}$ & & 100 & 0.00298 & 0.00323 \\
\hline CF10 & & 100 & 0.00259 & 0.00298 \\
\hline CF20 & 0.45 & 100 & 0.003 & 0.00339 \\
\hline CF30 & & 100 & 0.00323 & 0.00397 \\
\hline CF40 & & 100 & 0.00326 & 0.00398 \\
\hline $\mathrm{CF}$ & & 150 & 0.00307 & 0.00343 \\
\hline CF10 & & 150 & 0.00259 & 0.00303 \\
\hline CF20 & & 150 & 0.00307 & 0.00353 \\
\hline CF30 & & 150 & 0.0033 & 0.004 \\
\hline CF40 & & 150 & 0.00331 & 0.00409 \\
\hline $\mathrm{CF}$ & & 45 & 0.00267 & 0.002956 \\
\hline CF10 & & 45 & 0.00266 & 0.00301 \\
\hline CF20 & & 45 & 0.002735 & 0.003212 \\
\hline CF30 & & 45 & 0.002772 & 0.003267 \\
\hline CF40 & & 45 & 0.002778 & 0.003322 \\
\hline $\mathrm{CF}$ & & 100 & 0.0031 & 0.00333 \\
\hline CF10 & & 100 & 0.0027 & 0.003076 \\
\hline CF20 & 0.5 & 100 & 0.003175 & 0.003497 \\
\hline CF30 & & 100 & 0.003372 & 0.004092 \\
\hline CF40 & & 100 & 0.0034 & 0.004097 \\
\hline $\mathrm{CF}$ & & 150 & 0.0032 & 0.00354 \\
\hline CF10 & & 150 & 0.002699 & 0.003121 \\
\hline CF20 & & 150 & 0.0032 & 0.003639 \\
\hline CF30 & & 150 & 0.00343 & 0.004164 \\
\hline CF40 & & 150 & 0.003452 & 0.004213 \\
\hline $\mathrm{CF}$ & & 45 & 0.00278 & 0.00309 \\
\hline CF10 & & 45 & 0.00278 & 0.00315 \\
\hline CF20 & & 45 & 0.00285 & 0.00336 \\
\hline CF30 & & 45 & 0.00289 & 0.00342 \\
\hline CF40 & & 45 & 0.00291 & 0.00348 \\
\hline $\mathrm{CF}$ & & 100 & 0.00323 & 0.00349 \\
\hline CF10 & & 100 & 0.00282 & 0.00322 \\
\hline CF20 & 0.55 & 100 & 0.00331 & 0.00366 \\
\hline CF30 & & 100 & 0.00352 & 0.00428 \\
\hline CF40 & & 100 & 0.00355 & 0.00429 \\
\hline $\mathrm{CF}$ & & 150 & 0.00334 & 0.00371 \\
\hline CF10 & & 150 & 0.00282 & 0.00327 \\
\hline CF20 & & 150 & 0.00334 & 0.00381 \\
\hline CF30 & & 150 & 0.00358 & 0.00436 \\
\hline CF40 & & 150 & 0.0036 & 0.00441 \\
\hline
\end{tabular}


$9.67 \%, 23.03 \%, 7.88 \%$ and $19.01 \%$ more than those of the CF specimen too. Subsequently, it may be concluded that using fly ash and exposing to cycles of freezing and thawing results in softer concrete. But, in the case of CF10 specimen, the strain at the peak stress and ultimate strain in different cycles of freezing and thawing are very close to each other and it may be concluded that the optimum percent of substituting of fly ash instead of Portland cement is about $10 \%$.

Variation of $\left(\varepsilon_{0}\right)$ and $\left(\varepsilon_{c u}\right)$ of the frozen-thawed concrete specimens are shown in Fig. 9 and Fig. 10.

As it observed, with increasing the amount of fly ash and cycles of freezing and thawing, these strains increase too. In the case of CF10 specimen, the increasing rate of the strains is very slow, and the results are very close to each other. Moreover, in CF30 and CF40 specimens, the results are very close to each other and the ultimate strain of the specimens with 45 cycles of freezing and thawing is about $7.5 \%$ less than that of specimen with no cycles of freezing and thawing. It must be noted that specimens with no cycles of freezing and thawing are tested after 28 days and the specimens with 45 cycles of freezing and thawing

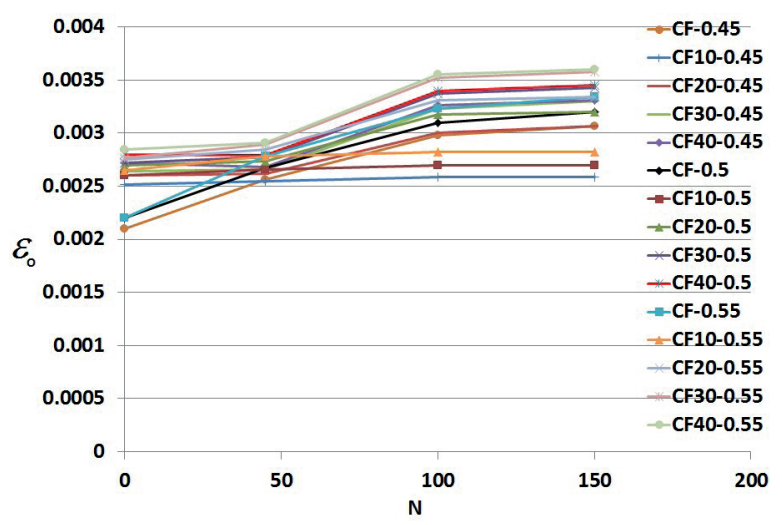

Fig. 9 Variation of the $\left(\varepsilon_{0}\right)$ of the frozen-thawed concrete specimens

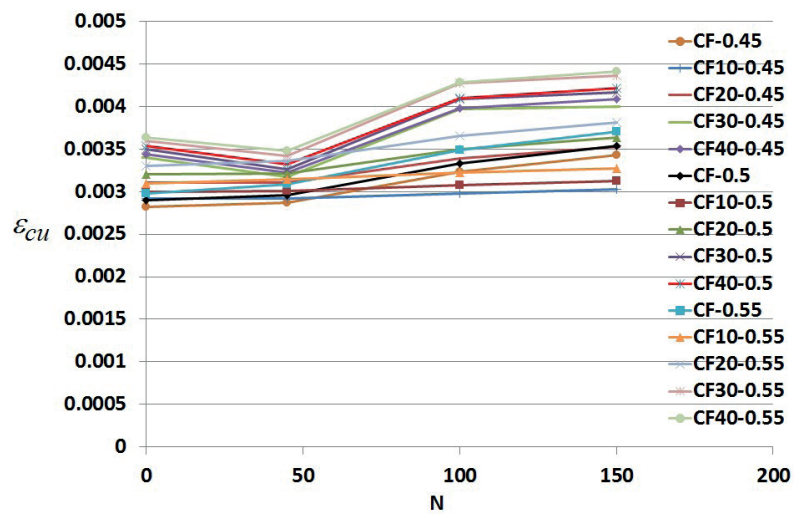

Fig. 10 Variation of the $\left(\varepsilon_{c u}\right)$ of the frozen-thawed concrete specimens tested after 21 days. Therefore, it may be concluded that using $10 \%$ of fly ash instead of Portland cement concludes to stable amounts for the above strains.

Substituting the 10 percent of the weight of cement by fly ash, would lead to smaller amount of freezable water and finer pore structure, resulting in lower water frozen rate, smaller ice formation amount, and finally better resistance to freezing and thawing cycles.

\section{Numerical investigations 4.1 Model of Duan et al.}

Many compressive stress-strain equations have been developed by different researchers for plain concrete. In this paper, the equation proposed by Duan et al. [6] (Eq. (2)) is used as the basic model equation. This model has been suggested for the frozen-thawed concrete and two independent parameters including and make it convenient to simulate the stress-stain curve for deteriorated concrete. Concave-up part of the stress-strain curves at the beginning of loading for frozen-thawed concrete can be achieved in this model. This model has been proposed for concrete cubic strength range from 30 to $50 \mathrm{MPa}$. But the effect of fly ash has been ignored in Eq. (2).

$$
\begin{aligned}
& \sigma / f_{C}=\left\{\begin{array}{l}
a_{D}\left(\varepsilon_{C} / \varepsilon_{0}\right)+\left(3-2 a_{D}\right)\left(\varepsilon_{C} / \varepsilon_{0}\right)^{2}+ \\
\left(a_{D}-2\right)\left(\varepsilon_{C} / \varepsilon_{0}\right)^{3}
\end{array}\right\}, 0 \leq \varepsilon_{C} / \varepsilon_{0} \leq 1 \\
& \sigma / f_{C}=\left(\varepsilon_{C} / \varepsilon_{0}\right) /\left[b_{D}\left(\left(\varepsilon_{C} / \varepsilon_{0}\right)-1\right)^{2}\right], \varepsilon_{C} / \varepsilon_{0} \geq 1 .
\end{aligned}
$$

where

$a_{D}=\left\{\left(6.474 \times 10^{7}\right) N^{2}-\left[0.5975 \times \exp \left(-0.1039 f_{c u}\right)\right] N+1\right\} a_{0}$

and

$b_{D}=\left\{\begin{array}{l}-\left[5.8159 \times \exp \left(-0.3078 f_{c u}\right)\right] N^{2} \\ +\left[14.097 \times \exp (-0.1803) f_{c u}\right] N+1\end{array}\right\} b_{0}$

Comparisons between the data obtained by the model of Duan et al. [6] and the present test results for concrete specimens with no fly ash exposing different cycles of freezing and thawing are presented in Fig. 11. From Fig. 11, it is observed that the stress-strain behavior of the concrete with no cycles of freezing and thawing is very close to that of the model of Duan et al. [6] and the maximum difference is about $1.82 \%$. Cycles of freezing and thawing concludes to more difference between test results and numerical model especially after the concave part of the curves at the beginning of the loading. But as can be seen from the Fig. 11, the model of Duan et al. [6] reveals 
relative good agreement with the experimental data. The values of $a_{D}$ and $b_{D}$ which were used for the numerical model is presented in Table 7 according to Eq. (2).

As it shown, the compressive behavior of CF-N $=100$ and CF-N $=150$ is very close to each other in both experimental and numerical investigations. Moreover, these specimens indicate more concave part at the beginning of the loading than that of the specimen with 45 cycles of freezing and thawing.

\subsection{Proposed model}

Based on characteristics of the experimental normalized stress-strain curves of the concrete specimens with fly ash exposing different cycles of freezing and thawing (Fig. 8), a polynomial equation (order 4) is proposed for modeling of the test results according to Eq. (3).

$\sigma / f_{c}=\left\{\begin{array}{l}a\left(\varepsilon_{C} / \varepsilon_{0}\right)+b\left(\varepsilon_{C} / \varepsilon_{0}\right)^{2}+c\left(\varepsilon_{C} / \varepsilon_{0}\right)^{3} \\ +d\left(\varepsilon_{C} / \varepsilon_{0}\right)^{4}\end{array}\right\}$,

where $a, b, c$, and $d$ are parameters to control the shape of the stress-strain curves and depend to amount of fly ash and cycles of freezing and thawing. For example, the comparison between experimental results and the proposed model of CF and CF10 specimens under different cycles of freezing and thawing is shown in Fig. 12 and Fig. 13.

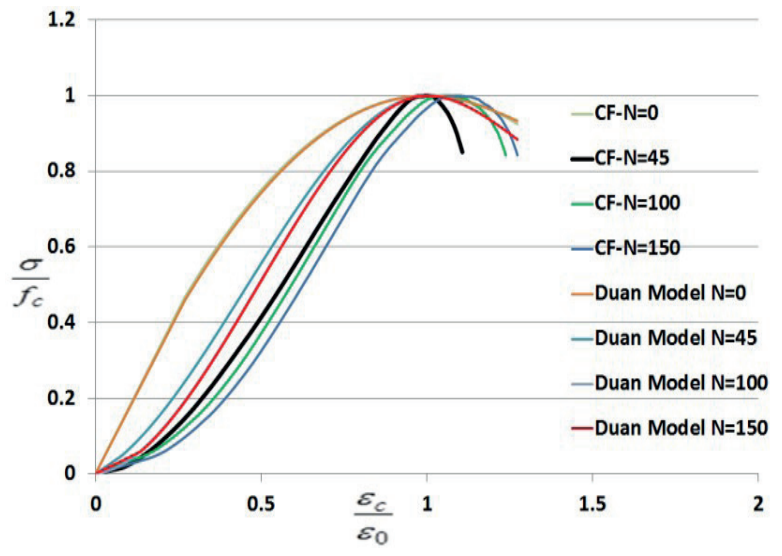

Fig. 11 Comparison of the test results and the model of Duan et al. [6] for concrete specimens without fly ash

Table 7 The values of $a_{D}$ and $b_{D}$ in the model of Duan et al. [6]

\begin{tabular}{lcc}
\hline Specimen & $a_{D}$ & $b_{D}$ \\
\hline $\mathrm{CF}-\mathrm{N}=0$ & 1.942 & 1.222 \\
$\mathrm{CF}-\mathrm{N}=45$ & 0.877 & 2.242 \\
$\mathrm{CF}-\mathrm{N}=100$ & 0.192 & 2.831 \\
$\mathrm{CF}-\mathrm{N}=150$ & 0.156 & 2.738 \\
\hline
\end{tabular}

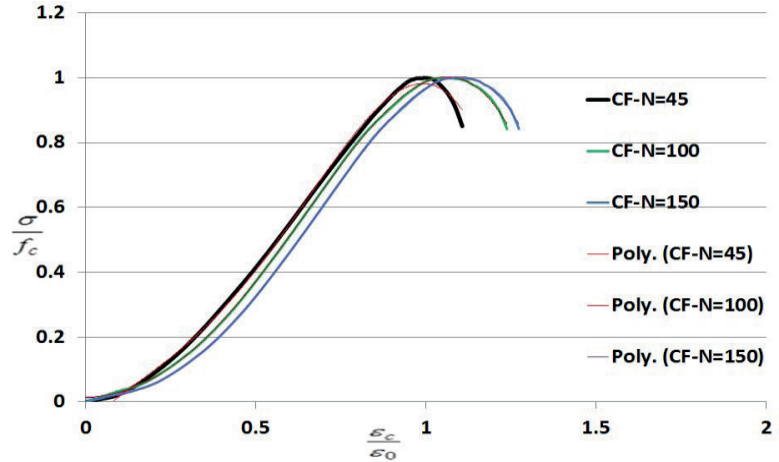

Fig. 12 Comparison between experimental results and the proposed model of CF specimens

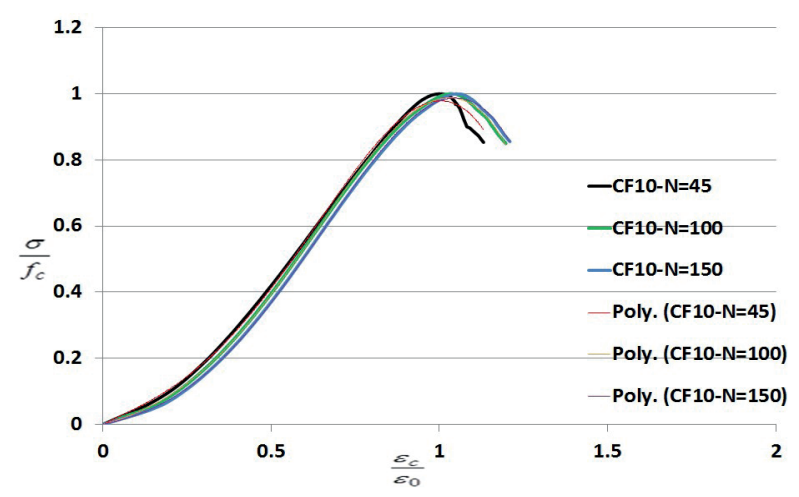

Fig. 13 Comparison between experimental results and the proposed model of CF10 specimens

As it observed, there is a good agreement between test results and the proposed model, and the differences are less than $5 \%$. Values of a, b, c, and d for the whole specimens are presented in Table 8 too.

Table 8 Values of $a, b, c$ and din the proposed model

\begin{tabular}{lcccc}
\hline Specimen & $a$ & $b$ & $c$ & $d$ \\
\hline CF-N $=45$ & 0.3489 & 0.1814 & 2.5433 & -2.0956 \\
CF-N $=100$ & 0.1547 & 0.8534 & 1.3188 & -1.3388 \\
CF-N $=150$ & 0.0696 & 0.7744 & 1.4428 & -1.3185 \\
CF10-N $=45$ & 0.4877 & 0.2293 & 2.871 & -2.151 \\
CF10-N $=100$ & 0.2831 & 0.4792 & 1.8744 & -1.6556 \\
CF10-N $=150$ & 0.2192 & 0.4891 & 1.8945 & -1.625 \\
CF20-N $=45$ & -0.1562 & 2.1131 & -0.0561 & -0.9147 \\
CF20-N $=100$ & -0.6589 & 4.086 & -2.7039 & 0.2567 \\
CF20-N $=150$ & -0.8065 & 3.9499 & -2.305 & 0.1179 \\
CF30-N $=45$ & -0.1873 & 2.0916 & -0.268 & -0.6622 \\
CF30-N $=100$ & -0.532 & 3.0543 & -1.424 & -0.1462 \\
CF30-N $=150$ & -0.5781 & 2.9598 & -1.2529 & -0.1952 \\
CF40-N $=45$ & -0.7596 & 4.1466 & -2.6962 & 0.2764 \\
CF40-N $=100$ & -1.0884 & 4.557 & -2.9893 & 0.4403 \\
CF40-N $=150$ & -1.1781 & 4.4468 & -2.7345 & 0.3551 \\
\hline
\end{tabular}




\section{Conclusions}

Based on the experimental work and the numerical analysis of the results, the following conclusions can be drawn:

1. Using fly ash in concrete concludes to more $\left(\varepsilon_{0}\right)$ and $\left(\varepsilon_{c u}\right)$ values than those of plain concrete. Maximum $\left(\varepsilon_{0}\right)$ and $\left(\varepsilon_{c u}\right)$ belong to CF40 specimen and are about $31.82 \%$ and $22.07 \%$ more than those of CF specimen respectively.

2. Exposing to freezing and thawing cycles, concludes to more $\left(\varepsilon_{0}\right)$ and $\left(\varepsilon_{c u}\right)$ than those of concrete with no cycles of freezing and thawing. Hence, it may be con-

\section{References}

[1] ACI Committee "ACI 232.2R-96 Use of fly ash in concrete", American Concrete Institute, Farmington Hills, MI, USA, 1996.

[2] Knutsson, A. "Freeze/thaw durability of concrete with fly ash", MSc Thesis, Chalmers University of Technology, 2010.

[3] Fagerlund, G. "Effect of air-entraining and other admixtures on the salt-scaling resistance of concrete", In: International Seminar on Some Aspects of Admixtures and Industrial By-Products on the Durability of Concrete, Göteborg, Sweden, 1986, pp. 33-39.

[4] Müller, C., Severins, K. "Durability of concretes made with cements containing fly ash", Concrete technology reports, Federal Ministry for Economic Affairs and Technology, Düsseldorf, Germany, 2007.

[5] Kosior-Kazberuk, M., Józwiak-Niedzwiedzka, D. "Influence of Fly Ash From Co-Combustion of Coal and Biomass on Scaling Resistance of Concrete", Archives of Civil Engineering, 56(3), pp. 239-254, 2010. https://doi.org/10.2478/v.10169-010-0013-x

[6] Duan, A., Jin, W., Qian, J. "Effect of freeze-thaw cycles on the stress-strain curves of unconfined and confined concrete", Materials and Structures, 44, pp. 1309-1324, 2011. https://doi.org/10.1617/s11527-010-9702-9

[7] Liu, J., Qiu, Q., Xing, F., Pan, D. "Permeation Properties and Pore Structure of Surface Layer of Fly Ash Concrete", Materials, 7(6), pp. 4282-4296, 2014.

https://doi.org/10.3390/ma7064282

[8] Nagaratnam, B. H., Faheem, A., Rahman, M. E., Mannan, M. A., Leblouba, M. "Mechanical and Durability Properties of Medium Strength Self-Compacting Concrete with High-Volume Fly Ash and Blended Aggregates", Periodica Polytechnica Civil Engineering, 59(2), pp. 155-164, 2015.

https://doi.org/10.3311/PPci.7744

[9] Wang, D., Zhou, X., Meng, Y., Chen, Z. "Durability of concrete containing fly ash and silica fume against combined freezing-thawing and sulfate attack", Construction and Building Materials, 147, pp. 398-406, 2017. https://doi.org/10.1016/j.conbuildmat.2017.04.172

[10] Ma, Z., Zhao, T., Yang, J. "Fracture Behavior of Concrete Exposed to the Freeze-Thaw Environment", Journal of Materials in Civil Engineering, 29(8), 2017. https://doi.org/10.1061/(ASCE)MT.1943-5533.0001901 cluded that using fly ash and exposing to cycles of freezing and thawing results in softer concrete.

3. Strain at the peak stress and ultimate strain in different cycles of freezing and thawing of the CF10 specimens are very close to each other and it may be concluded that the optimum percent of substituting of fly ash instead of Portland cement is about $10 \%$.

4. A polynomial equation (order 4 ) is proposed for modeling of the test results. There is a good agreement between the test results and proposed model and the difference is less than $5 \%$.

[11] Cheung, J., Roberts, L., Liu, J. "Admixtures and sustainability", Cement and Concrete Research, 114, pp. 79-89, 2018. https://doi.org/10.1016/j.cemconres.2017.04.011

[12] Wang, D., Zhou, X., Fu, B., Zhang, L. "Chloride ion penetration resistance of concrete containing fly ash and silica fume against combined freezing-thawing and chloride attack", Construction and Building Materials, 169, pp. 740-747, 2018. https://doi.org/10.1016/j.conbuildmat.2018.03.038

[13] Liu, F., You, Z., Yang, X., Wang, H. "Macro-micro degradation process of fly ash concrete under alternation of freeze-thaw cycles subjected to sulfate and carbonation", Construction and Building Materials, 181, pp. 369-380, 2018. https://doi.org/10.1016/j.conbuildmat.2018.06.037

[14] Fantilli, A. P., Tondolo, F., Chiaia, B., Habert, G. "Designing Reinforced Concrete Beams Containing Supplementary Cementitious Materials", Materials, 12(8), Article number: 1248, 2019. https://doi.org/10.3390/ma12081248

[15] Nguyen, C. V., Lambert, P., Tran, Q. H. "Effect of Vietnamese Fly Ash on Selected Physical Properties, Durability and Probability of Corrosion of Steel in Concrete", Materials, 12(4), Article number: 593, 2019.

https://doi.org/10.3390/ma12040593

[16] ASTM "ASTM C33 / C33M - 18 Standard specification for concrete aggregates", ASTM International, West Conshohocken, PA, USA, 2018.

https://doi.org/10.1520/C0033_C0033M-18

[17] ASTM "ASTM C618 - 05 Standard specification for coal fly ash and raw or calcined natural pozzolan for use in concrete", ASTM International, West Conshohocken, PA, USA, 2005. https://doi.org/10.1520/C0618-05

[18] ASTM "ASTM C666 / C666M - 03(2008) Standard test method for resistance of concrete to rapid freezing and thawing", ASTM International, West Conshohocken, PA, USA, 2008. https://doi.org/10.1520/C0666_C0666M-03R08

[19] Domone, P. L. J., Illston, J. M. (eds.) "Construction Materials, Their nature and behavior", Spon Press, New York, USA, 2010. 